\title{
Study of Surgical Problems In Hiv/Aids Patients
}

\author{
Prof.Dr.K.Sathyabama,M.S., ${ }^{1}$ Prof.Dr.V.Kopperundevi,M.S., ${ }^{2}$ \\ Dr.V.Meenakshi Sundaram ${ }^{3}$ \\ ${ }^{\text {I}}$ (Professor, Department of General Surgery, Thanjavur Medical college, Thanjavur, TN MGR University, \\ Tamilnadu, India) \\ ${ }^{2}$ (Associate Professor, Department of General Surgery, Thanjavur Medical college, Thanjavur) \\ 3 ( (MS) Post graduate, Department of General Surgery, Thanjavur Medical college, Thanjavur)
}

\begin{abstract}
HIV constitutes one of the most difficult challenges faced by the healthcare Professionals today. According to a paper from UNAIDS/WHO in 2015, there are about 36.7 million HIV infected patients currently in the entire world. There are about 2.1 million who were newly diagnosed worldwide. 1.1 million patients expired due to AIDS in 2015.Potent anti retroviral therapy (ART) has significantly increased longevity among HIV-infected patients. As this patient population grows older, an increased incidence of surgical illness is likely and 20-25\% of them may need a Surgical intervention.

Aim : To analyse the incidence of age and sex, co morbid illness, duration of ART treatment, clinical presentation of surgical problem, including surgical emergencies and their management and outcome.This is a Prospective study conducted in the department of General Surgery, in association with ART centre from July2015 to August 2016. About 60 patients were included in this study with information of age sex,HIV diagnosed at the time of surgical problem or on ART treatment presented with surgical illness, duration of ART treatment, surgical procedure done and their outcome.
\end{abstract}

Keywords:HIV , ART, Surgical disease

Inclusion criteria: All patients presenting to the surgical Department / Speciality Department /ART OPD with surgical illness were included.

Exclusion criteria:The patients of medical/ medical speciality and OPD were excluded. Patient with Medical conditions in ART OPD were excluded. Patients less than 12 years of age also excluded.

\section{INTRODUCTION}

AIDS, Acquired Immuno Deficiency Syndrome is a clinical syndrome caused by Human Immunodeficiency Virus [HIV]. HIV viruses are RNA viruses that belong to the family Retroviridae. RETRO means backward in Latin. The viruses of this family possess an enzyme called as Reverse transcriptase. The function of reverse transcriptase is that they produce DNA copy of RNA genome in the cells of their host. Hence reverse transcriptase enzyme is the characteristic of these viruses .

The Retroviridae family is divided into $2 \mathrm{sub}$ families :Orthoretrovirinae and Spumaretrovirinae. There are seven genera in this particular family, out of these 7, only 2 family has retroviruses that infect human. They are the Lentivirus and Retrovirus.

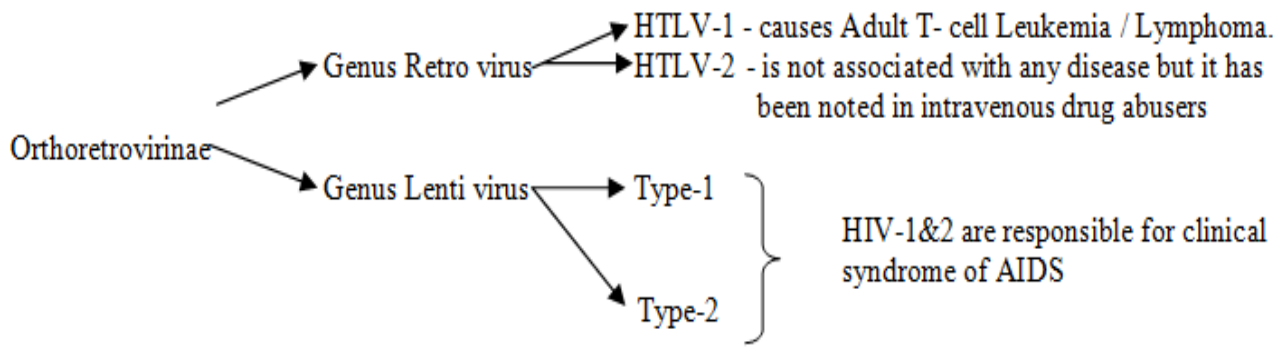

The first incidence of this new syndrome came in 1981 withtwo reports from New York and Los Angeles of the outbreak of two rare diseases namely Kaposi sarcoma and pneumocystiscarinii pneumonia .In 1983lucmontagnier from Pasteur instituteisolated a retrovirus from west African patient with persistent generalized lymphadenopathy and called Lymphadenopathy associated virus . In 1984 Robert Gallo from National Institute of Health, USA called it Human T-cell Lymphotropic Virus type3. In 1985 ELISA became available for the detection of HIV. In 1986 the term HIV was coined. 
After its entry into the blood stream, HIV comes in contact with the suitable host cells mainly the CD4 lymphocytes. Once it enters the cell, RNA is transcribed by reverse transcriptase into DNA (provirus). The provirus is integrated in the genome of infected cell causing latent infection. Long and variable incubation time of HIV infection is because of initiated and release of progeny virions to infect other cells. If infected, HIV can be isolated from blood, cell free plasma, semen, breast milk, urine, tears, cervical secretions and saliva.

Infection causes damage to T4 lymphocytes. T4 cells are decreased in numbers and T4:T8 (helper :suppressor) ratio is reversed. Viral infection can depress the function of infected cell without damaging. This leads to the recognized damping effects on Cell Mediated Immunity. Functions of other cells (macrophage and monocytes) are affected apparently due to the absence of secretion of activating factors by $\mathrm{T} 4$ lymphocytes.

Clinical manifestations of HIV infections are due to failure of immune responses. This renders the patient susceptible to life threatening opportunistic infections and malignancies Degenerative neurological lesions and Dementia can also be seen in AIDS. This may be because of the direct effect of HIV on Central Nervous System.Many of these people have no signs or symptoms and are unaware that they are infected. The infection is lifelong and, once acquired, can be transmitted to others. Three modes of HIV transmission have been classified by World Health Organisation(WHO): sexual, parenteral (through direct inoculation of blood or blood products ), and perinatal ( from an infected women to a foetus or infant, before, during or after birth).

\subsection{Clinical course of HIV infection is as follows: \\ 1.1.1Acute HIV infection}

The illness is mainly characterized by acute onset of fever, malaise ,myalgia , skin rash, arthralgia , sore throat, and lymphadenopathy. Peripheral blood shows lymphocytosis. Viral nucleic acid or viral p24 antigen can be detected during acute infection. HIV antibodies are negative at the onset of illness but become positive during the course.

\subsubsection{Seroconversion illness}

Seroconversion illness lasts for $2-6$ weeks and other phases will take at least 10 years on an average 1.1.3. Asymptomatic phase

It includes all infected persons who are clinically normal. They show positive HIV antibody tests, and are infectious.

\subsubsection{Symptomatic phase}

When CD4+ $\mathrm{T}$ lymphocyte count decreases below 400 per $\mathrm{mm}^{3}$ the patient can develop symptoms like diarrhoea, night sweats, opportunistic infections, weight loss and fever . During this condition some patients may develop an illness known as AIDS related complex or condition(ARC).

\subsubsection{AIDS}

When CD4 + cells fall below 200per $\mathrm{mm}^{3}$, the titre of virus will increase markedly and there will be irreversible breakdown of immune defence mechanisms, this called as AIDS and it is the terminal stage of HIV infection.

\subsubsection{Death}

Patients with HIV disease die of infections other than HIV e.g. opportunistic infections and malignancies like primary CNS lymphoma. Progressive multifocal leukoencephalopathy, myelopathy, Dementia, peripheral neuropathy, severe encephalopathy, motor disturbances and diminished concentration may develop during HIV infections.

\subsection{Laboratory Diagnosis:}

Laboratory diagnosis of HIV infection includes specific tests for the virus and tests for immunodeficiency.

\subsubsection{Specific tests for HIV infections:}
i. Antibody detection
ii. Detection of viral nucleic acid
iii. Antigen detection : p24 antigen
iv. Virus isolation

\subsubsection{Non - specific tests:}

1) Total and differential leucocyte count:

In AIDS , there is leucopenia with a lymphocyte count less than 400 per $\mathrm{mm}^{3}$

2) Platelet count:

There is thrombocytopenia in patients with AIDS

3) T-lymphocytes subset assays: 
The normal CD4:CD8 T-cell ratio of 2:1, is reversed to 0.5:1 in cases of AIDS count of CD4 lymphocytes falls below $200 \mathrm{~mm}^{3}$.

4) $\operatorname{IgG}$ and $\operatorname{Ig} A$ levels:

Both IgG and IgA levels are raised

5) Skin tests for CMI:

Cell mediated immunity is decreased as seen from tuberculin test or other skin tests for CMI

The tests used for monitoring course of HIV infection includes

1. Measurement of HIV RNA2. CD4+T cell count

The most important among these is CD 4+ T cell count that indicates immunological competence of the patients. Counts below $350 / \mathrm{mm} 3$ indicates progression of disease and the need for antiretroviral therapy

\subsection{Antiviral Treatment:}

Specific treatment with antiretroviral drugs is the mainstay in the HIV management

HAART ( Highly Active Antiretroviral Therapy ) are highly effective in the inhibition of the replication of HIV in HIV infected individuals. The Anti Retro viral drugs include both nucleoside inhibitors (zidovidine lamivudine) and non nucleoside inhibitors of enzyme reverse transcriptase, (delaviridine, nevirapine) viral protease inhibitors, (indinavir, nelfinavir) integrase inhibitor (raltegravir )fusion inhibitors(Enfuviritide (T20) and entry inhibitor(CCR5-Co-receptor antagonist Maraviroc (MVC). These drugs are used in the form of monotherapy or in various combinations.

Effective antiretroviral therapy (ART) for people living with HIV has resulted in a life expectancy that approaches that of the general population. Hence both emergency and elective surgical procedures are common to HIV patients also.Reliable predictors of surgical outcome depend up on nutritional status of the patient (s.albumin $<2.5 \mathrm{~g} / \mathrm{dl}$ ), presence or absence of organ failure, than CD4count or viral load. Some studies have shown poorer surgical outcomes for individuals with low CD4 counts, although this is not a consistent finding. Viral suppression also has not been conclusively shown to improve surgical outcomes; However, in the setting of elective surgery, it is still recommended that ART be optimized preoperatively. Surgical risk assessment for HIV-infected individuals is highly individualized, and all aspects of the HIV-infected patient's clinical profile, including the indication for surgery, should be evaluated and discussed with the patient. The preoperative evaluation of HIV-infected patients should be the same as that for non-HIV-infected patients with extra focus on the LFT,RFT cardiac status, history of previous infection with MRSA. Universal surgical precautions that apply to all patients should be followed. ART should be continued in the perioperative period. For patients who are unable to receive medications orally (NPO), a period of withholding ART will be necessary. HIV -infected patients are at increased risk for hypercoagulability and may be at increased risk for thromboembolic complications in the postoperative period and hence early ambulation is advised.

\section{II.Results}

The ART centre at Thanjavur Medical College, has a statistics of about 383 new case of HIV was diagnosed and registredduring the period of July 2015 to August 2016.In this Male - 217, Female - 154, transgender- 1 , Male children -8, Female children - 3.About 60 patients with HIV including newly detected had surgical problems were included in this study.

\subsection{Age Incidence of the patients:}

Age of the selected patients ranged 20-60 years with most of the patients between 41-50 years (22 patients $=36.66 \%$ of the patients).

Table.1 Age Distribution of the patient

\begin{tabular}{|c||c|c|}
\hline \hline Age & $\begin{array}{c}\text { No.of. } \\
\text { Patients }\end{array}$ & Percentile \\
\hline \hline $\mathbf{2 1 - 3 0}$ & 10 & $16.67 \%$ \\
\hline $\mathbf{3 1 - 4 0}$ & 18 & $30 \%$ \\
\hline $\mathbf{4 1 - 5 0}$ & 22 & $36.66 \%$ \\
\hline $\mathbf{5 1 - 6 0}$ & 10 & $16.67 \%$ \\
\hline
\end{tabular}

\subsection{Sex Incidence:}

Among the total 60 patients $68 \%$ (41 patients) were males and 32\% (19 patients) were females. The ratio of male to female is $2: 1$ and the predominant group is males. 
Table 2: Sex Distribution of the Patient

\subsection{Occupation Details:}

\begin{tabular}{||l||c||c|}
\hline \multicolumn{1}{|c||}{ Sex } & $\begin{array}{c}\text { No.of } \\
\text { Patients }\end{array}$ & Percentage \\
\hline \hline Male & 41 & $68.33 \%$ \\
\hline Female & 19 & $31.67 \%$ \\
\hline
\end{tabular}

The occupation of the patients were variable. About 27\%(16 patients) of the patients were labourers and about $15 \%$ of the patients ( 9 patients) were drivers. $8.33 \%$ of them (5 patients) were sex Workers.

Table 3: Occupation distribution of patients
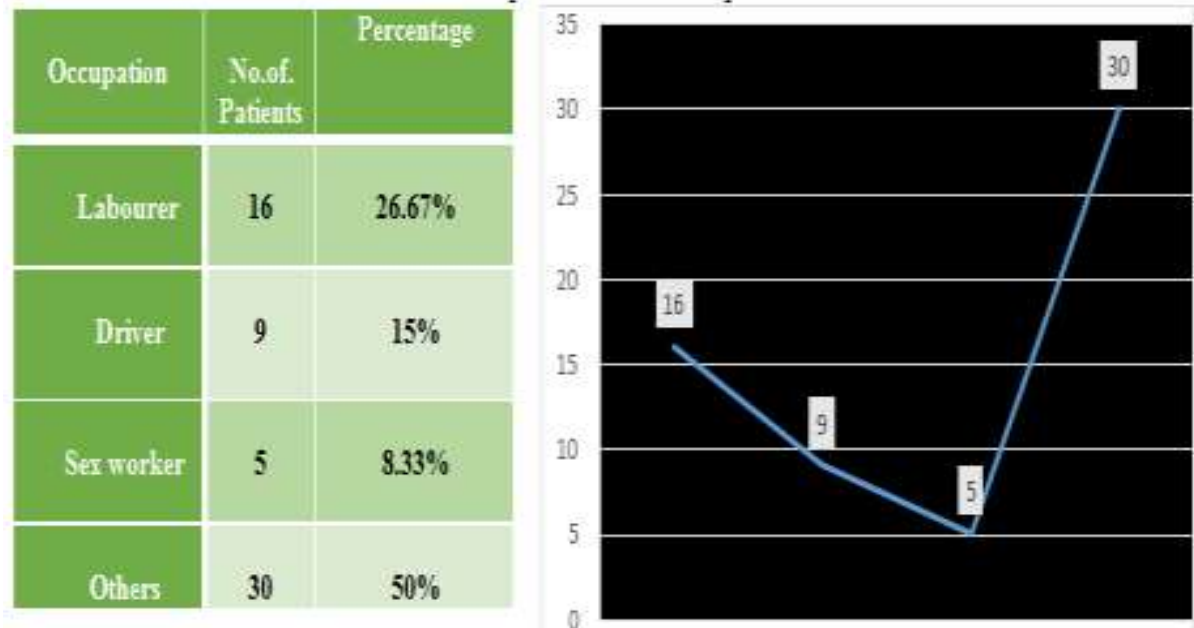

$$
\text { LABOURER DRIVER SEXWORKER OTHERS }
$$

\subsection{Comorbid Illness Incidence:}

Table 4: Diversity of comorbid illness among the patients.

\begin{tabular}{|c|c|c|}
\hline Comorbid illness & $\begin{array}{c}\text { No.of } \\
\text { Patients }\end{array}$ & Percentage \\
\hline \hline Diabetes mellitus & 12 & $20 \%$ \\
\hline \hline Pulmonary tb & 8 & $13.33 \%$ \\
\hline \hline Hypertension & 7 & $11.67 \%$ \\
\hline \hline COPD & 4 & $6.67 \%$ \\
\hline \hline Diabetes \& hypertension & 2 & $3.33 \%$ \\
\hline \hline Bronchiectasis & 1 & $1.67 \%$ \\
\hline \hline Seizure disorder & 1 & $1.67 \%$ \\
\hline Nil & 25 & $41.66 \%$ \\
\hline
\end{tabular}

\subsection{Clinical Presentation:}

The various clinical presentation among the patients are as follows:

1. Inguinal Hernia - 6 cases

2. GIT Elective

a) Haemorrhoids - 2 cases

b) Duodenal ulcer - 1 case

c) Abdomino pelvic cyst - 1 case

d) Right lobe liver abscess -1 case

\section{GIT Emergency}

a) Appendicitis(abscess/perforation) - 3 cases

b) Duodenal ulcer perforation - 2 cases 
c) Obstructed incisional Hernia - 1 case

4. Infectious(Tuberculosis)

a) Obstructive Hydrocephalus - 1 case

b) Cold abscess neck - 1 case

c) Psoas abscess - 1 case

d) Empyema - 2 cases

\section{Infectious (Non-Tuberculosis)}

a) Abscess

i. Penile

ii. Parotid

iii. Perinephric

iv. Ruptured splenic

v. Right Inguinal

vi. Water can perineum / periurethral

b) Other Infections

i. AGE

ii. Cervicitis

iii. RightEpididymoorchitis

iv. Syphilitic penile ulcer

v. Cellulitis left back

vi. Necrotizing lymph adenitis neck node

vii. Right lower limb cellulitis

viii. Urosepsis

ix. Esophageal candidiasis

x. Cystitis

xi. Cervical lymph adenitis

xii. Snake bite cellulitis

6. Malignancy

a) $\mathrm{Ca}$ Stomach with liver metastasis

b) Ca Cervix

c) $\mathrm{Ca}$ Caecum

d) $\mathrm{Ca}$ Stomach

e) $\mathrm{Ca}$ Caecum with liver metastasis

7. Trauma

a) 3 cases of road traffic accidents( 1 with head injury)

b) Accidental fall

8. Other Conditions:

a) Bilateral varicose vein

b) 2 cases of Deep Venous Thrombosis

c) Right lower limb Filariasis

d) 2 cases of sebaceous cyst

e) 2 cases of hydrocele

f) Benign Prostatic Hyperplasia

g) SOL Brain temporal lobe

Table 5: Diversity of clinical presentation among the patients

\begin{tabular}{||c|c|c||}
\hline $\begin{array}{c}\text { Clinical } \\
\text { presentation }\end{array}$ & $\begin{array}{c}\text { No.of. } \\
\text { Patients }\end{array}$ & Percentage \\
\hline Infectious(TB) & 5 & $8.33 \%$ \\
\hline Non-TB Infectious & 18 & $30 \%$ \\
\hline \hline Malignancy & 5 & $8.33 \%$ \\
\hline \hline Trauma & 4 & $6.67 \%$ \\
\hline
\end{tabular}




\begin{tabular}{||c||c||c|}
\hline Hernia & 6 & $10 \%$ \\
\hline \hline GIT elective & 5 & $8.33 \%$ \\
\hline \hline GIT emergency & 6 & $10 \%$ \\
\hline \hline Others & 11 & $18.34 \%$ \\
\hline
\end{tabular}

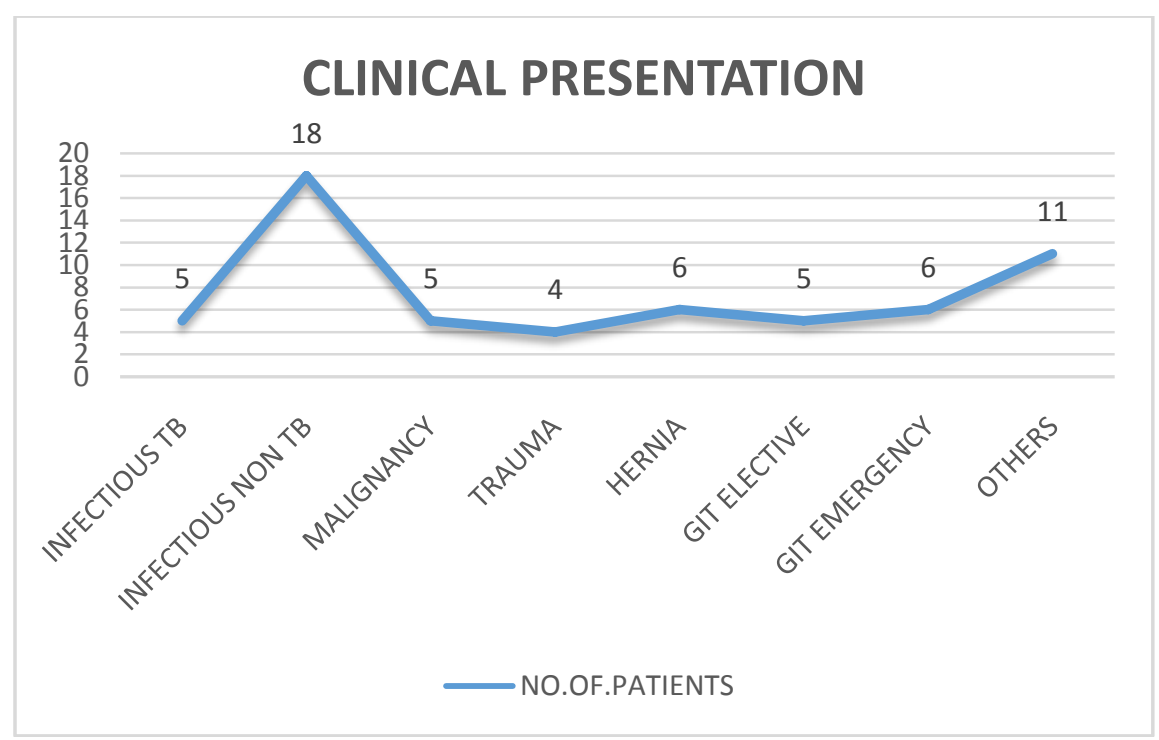

2.6 Incidence of system involved:

Table 6: Distribution of diseases based on the organ system

\begin{tabular}{||c|c|c|}
\hline Organ System & No.Of. Patients & Percentage \\
\hline GIT & 17 & $28.34 \%$ \\
\hline \hline Urogenital & 12 & $20 \%$ \\
\hline Others & 9 & $15 \%$ \\
\hline \hline Hernia & 6 & $10 \%$ \\
\hline \hline Accident & 5 & $8.33 \%$ \\
\hline \hline Soft Tissue & 4 & $6.67 \%$ \\
\hline \hline Lymph Nodes & 3 & $5 \%$ \\
\hline CNS & 2 & $3.33 \%$ \\
\hline RS/Lungs & 2 & $3.33 \%$ \\
\hline
\end{tabular}

2.7 No. of years on ART:

Table 7: ART distribution of patients.

\begin{tabular}{|c|c|c|}
\hline $\begin{array}{l}\text { No.of. Years } \\
\text { Since ART }\end{array}$ & $\begin{array}{c}\text { No.of. } \\
\text { Patients }\end{array}$ & Percentage \\
\hline \hline $0-4$ & 23 & $\mathbf{3 8 . 3 3 \%}$ \\
\hline \hline $5-8$ & $\mathbf{2 4}$ & $\mathbf{4 0 \%}$ \\
\hline \hline $9-12$ & 13 & $\mathbf{2 1 . 6 7 \%}$ \\
\hline
\end{tabular}

2.8 Treatment given:

Table 8: Diversity in the treatment given to the patients

\begin{tabular}{||c||c||c||}
\hline Treatment given to the patients & $\begin{array}{c}\text { No.of } \\
\text { Patients }\end{array}$ & Percentage \\
\hline \hline Operated/elective & 17 & $28.33 \%$ \\
\hline \hline Operated/emergency & 14 & $23.33 \%$ \\
\hline \hline Expired & 3 & \\
\hline
\end{tabular}




\begin{tabular}{|c|c|c|}
\hline & & $5 \%$ \\
\hline Chemotherapy & 2 & $3.33 \%$ \\
\hline ATT & 2 & $3.33 \%$ \\
\hline Absconded & 1 & $1.67 \%$ \\
\hline Radiological intervention & 1 & $1.67 \%$ \\
\hline Conservative management & 20 & $33.33 \%$ \\
\hline
\end{tabular}

\subsection{Surgical Management:}

Table 9: Distribution of operated patients

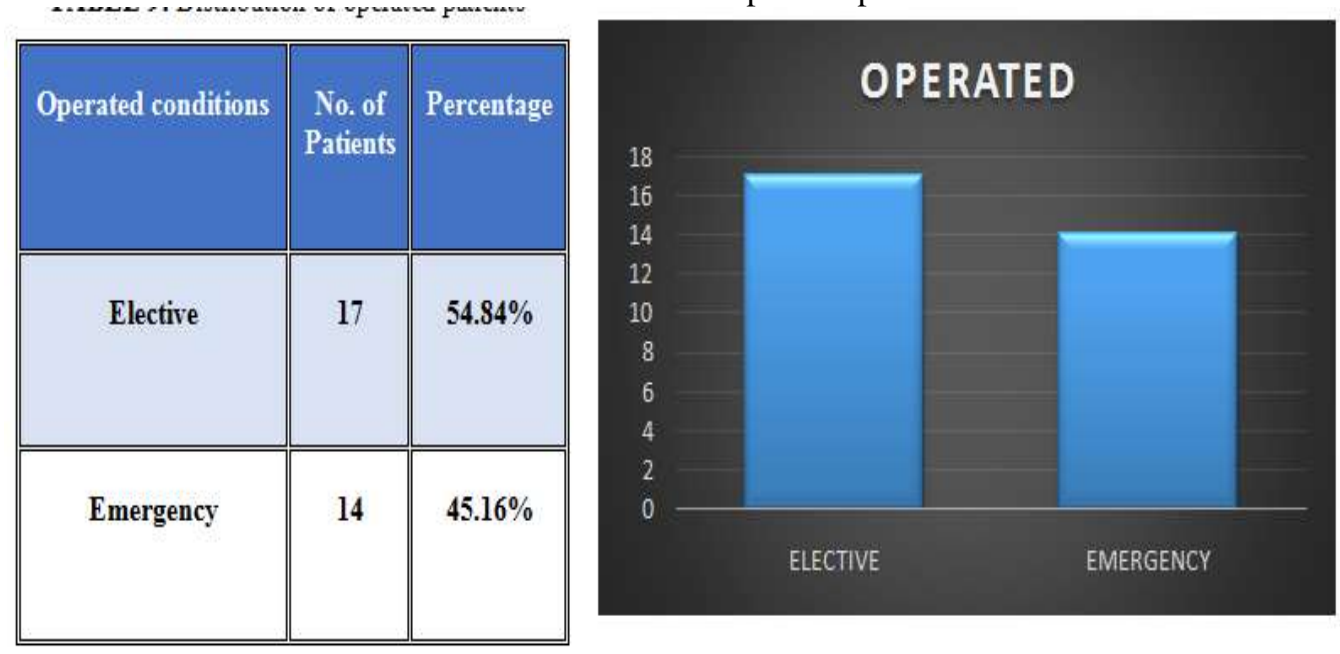

\section{Conclusion}

In This study

1. Male HIV patients had more surgical problems than Females.

2. The common age group is between 41-50 years

3. Majority of the patients are labourers.

4. Most of the patients in this study were on ART since 0-4 years and 5-8years

5. The common comorbid illness among HIV/AIDS patients is diabetes mellitus followed by pulmonary tuberculosis.

6. The commonest organ system involved among the surgical patients is gastro intestinal system.

7. About $52 \%$ of patients were operated among whom $28.33 \%$ were operated electively.

8. Among elective surgeries surgery for hernia is commonest.

9. Among the emergencies complicated appendicitis / abscess is common.

. LOW CD4 count suggesting that it is one of the triggering factors for HIV infected patients to develop various surgical pathologies. The management of the HIV patient with surgical problem has to be individualised and there is no technical difference in managing these individuals compared with the general population.

\section{References}

[1]. BavejaCP : textbook of Microbiology, $4^{\text {th }}$ edition, 2014.

[2]. Bailey RC et al : Male circumcision for HIV prevention in young men in Casuum, Kenya; A randomized controlled trial. Lancet $369 ; 643,2007$

[3]. Cohen MS, Pilcher CD; Amplified HIV transmission and new approaches to HIV prevention Infect Dis 191;1391,2005

[4]. Diffenbach CW, Fauci AS; Universal voluntary testing and treatment for prevention of HIV transmission. JAMA 301;2380,2009

[5]. Drumright $\mathrm{L}$ et al; Unprotected and intercourse and substance use among men who have sex with men and recent HIV infection. J AIDS 43;344,2006

[6]. Este JA,Telenti A;HIV entry inhibitors. Lancet 370;81,2007

[7]. FauciAS;Host factors and the pathogenesis of HIV -induced disease, Nature 384;529,19962

[8]. Arthos J et al: HIV-1 envelope protein binds to and signals through integrin $\alpha 4 \beta 7$, the gut mucosal honing receptor for peripheral $\mathrm{T}$ cells. Nature Immunol 9:301,2008. 
[9]. Benson CA et al: Treating opportunistic infections among the HIV-infected adults and adolescents. Recommendations from CDC, the National Institutes of Health, and the HIV Medicine Association/Infectious Diseases Society of America, MMWR53 (RR15):1,2004.

[10]. Brenner BG et al: High rates of forward transmission events after acute/early HIV-1 infection, J infect Dis 195:951, 2007.

[11]. CENTERS FOR DISEASE CONTROL AND PREVENTION: Revised guide lines for HIV Counseling,testing and referral.MMWRRecomm Rep54 (R-R-9):1,2001

[12]. Updated U.S.Public Health Service guidelines for the management of occupational exposures to HIV and recommendations for postexposureprophylaxis.MMWRRecomm Rep 54(R-R-9):1,2005

[13]. HIV/AIDS surveillance Report,2005;17(Revised ),2007.available at http://www.cdc.gov/hiv /

[14]. Revised recommendations for HIV testing of adults, adolescents and pregnant women in health-care settings.MMWRReccomRep 54(R-R-14):1,2006.

$[15]$

[16]. Essential components of a Comprehensive strategy to prevent Domestic HIV,2006. Available at http://www.cdc.gov/Hiv/resources/reports/comp_hiv_prev/index.htm

[17]. Health resources and services administration; National Institute of Health;HIV medicine association of the infectious diseases society of America; Incorporating HIV prevention into the medical care of persons living with HIV.MMWR Recomm Rep 52(R-R12): 1,2003

[18]. Centlivre $M$ et al: In the HIV -1 pathogenesis the die is cast during primary infection.AIDS 21:1,2007

[19]. Collins LS et al: MulticentricCastleman's disease in HIV infection. Int J STD AIDS 17:19,2006

[20]. Corey L : Synergistic copathogens -HIV-1andHSV-2.N Engl J Med 356:854,2007

[21]. Department of Health and services panel on anti-retroviral guiudelines for adults adolescents: Guidelines for the use of Antiretroviral agents in HIV -1- Infected Adults and Adolescents ,october10 2006 .Updates available at http;//www.aidsinfo.nih.gov

[22]. Dorak MT et al; transmission of HIV-1 and HLA-B allele sharingwithinserodiscordant heterosexual Zambian couples.Lancet363;2137,2004

[23]. Fellay J et al: A whole genome association study of major determinants for host control of HIV-1.Science 317 : $944,2007$.

[24]. Madiba TE, Muckart DJJ, Thomson SR. Human immunodeficiency disease: How should it affect surgical decision-making? World J Surg2009; 33:899-909

[25]. Shen YM, Frenkel EP. Thrombosis anda hypercoagulable state in HIV-infected patients. ClinApplThromb Hemost2004;10:277280 . 